\title{
UM BREVE PANORAMA DO HUMOR NOS QUADRINHOS FEMINISTAS SUECOS A PARTIR DA OBRA DE NINA HEMMINGSSON, MALIN BILLER E LIV STRONQUIST
}

\author{
A BRIEF OVERVIEW OF THE HUMOR IN SWEDISH FEMINIST COMICS FROM \\ THE WORK OF NINA HEMMINGSSON, MALIN BLLLER AND LIV STRONQUIST
}

\section{RESUMO}

A Suécia é um país que possui tradição tanto na produção quanto na participação das mulheres na cena dos quadrinhos. Mas, no início do século XXI estas mulheres passaram a ter um papel ainda maior graças a todo um contexto sócio-político que conduziu a Suécia a grandes mudanças. Foi importante nesse processo o movimento feminista e a disposição da sociedade em debater acerca da equidade de gênero. Os quadrinhos tiverem seu lugar nesse debate através de produções com um viés feminista, no qual o humor teve uma presença marcante. Para o presente artigo, utilizamos, como exemplo dessa produção, os quadrinhos de três autoras pertencentes a essa nova geração: Nina Hemmingsson, Malin Biller e Liv Strönquist. Por meio desses quadrinhos, notadamente satíricos, é possível notar a construção e descontração dos papéis de gênero assim como do próprio discurso feminista, que dá aos quadrinhos a qualidade de tecnologias de gênero.

Palavras-chave: Suécia, Histórias em Quadrinhos, gênero.

\begin{abstract}
Sweden is a country where we can see traditions both in production and in women's participation in comic books scene. However, in the early 21st century these women started to have a bigger role thanks to the socio-political context that led Sweden to great changes. The feminist movement and the society will to discuss about gender equality were important in this process. Comic books had their place in this discussion through feminist productions where humor had a strong presence. In this article, we had comics of three authors belonging to this new generation as examples of these productions: Nina Hemmingsson, Malin Biller and Liv Stronguist. By means of these comics, clearly satirical, it is possible to notice the construction and informality of the gender role as well as the feminist discourse itself which offers gender technology quality to the comics.
\end{abstract}

Keywords: Sweden, Comics, genre.

Natania A. S. Nogueira

Universidade Salgado de Oliveira (UNIVERSO). E-mail: nogueira.natania@gmail.com 


\section{Introdução}

Segundo Christophe Quillien, autor do livro Elles: Grandes aventurières et femmes fatales de la bande dessinée (2014), durante muito tempo, as mulheres não foram bem-vindas nos quadrinhos, nem como autoras, nem como personagens (QUILLET, 2015). A historiadora Michelle Perrot, em sua obra Minha História das Mulheres, chama a atenção para o silêncio das mulheres, um silêncio imposto por uma sociedade dominada pelos homens, que não se interessavam em contar esta história (PERROT, 2004: 17). Um silêncio que, pelo que se pode perceber, foi imposto a todas as áreas de atuação humana.

Mas, este panorama vem mudando especialmente nas últimas décadas, quando as mulheres têm deixado de ser a exceção, a excepcionalidade, para se tornarem protagonistas na cena dos quadrinhos, tanto na Europa quanto na América. A exemplo dessa ascensão das mulheres na cena dos quadrinhos no ocidente, trouxemos para este artigo o caso da Suécia, a partir da análise da obra e do percurso de três quadrinistas: Nina Hemmingsson, Malin Biller e Liv Strömquist. Essas três autoras destacam-se no campo do humor e tiveram um forte impacto sobre a produção de outras quadrinistas em seu país, tanto pela versatilidade quanto pela militância feminista.

Os quadrinhos feministas trazem à tona temas que fazem parte da vida daquele país, das relações entre homens e mulheres em situações cotidianas que envolvem um emaranhado de relações de poder. E, para entender esse processo, vamos utilizar a categoria gênero que, para Joan Scott (1989), é uma construção, um universo simbólico a partir do qual definimos a forma como vamos enxergar a nós mesmos(as) e a realidade em que vivemos. Um saber, uma percepção sobre as diferenças sexuais, é uma relação de poder que vai muito além da questão biológica (o sexo), alicerçada em hierarquias sociais, valores culturais, símbolos e significados.

Nos quadrinhos de humor das autoras analisadas, podemos identificar essas relações de poder e uma constante construção e reconstrução dos papéis de gênero que podem ser percebidas nas relações sociais mais básicas, como em uma conversa de bar, um passeio no parque ou uma ida ao supermercado. Um humor fortemente politizado e marcadamente feminista que pode causar estranhamento ao leitor brasileiro que emergiu em meio ao crescimento do movimento feminista na Suécia, notadamente nos anos de 1990.

Ainda pouco conhecida no Brasil, a produção de histórias em quadrinhos da Suécia vem ganhando o mundo na última década. Esta recente descoberta dos quadrinhos suecos foi possível graças à crescente publicação de autores e autoras daquele país tanto em países europeus quanto nas Américas e até no Japão. Os Suecos estão inovando em forma e narrativa e apostando na profissionalização de quadrinistas, que frequentam escolas de artes, onde são oferecidos cursos especificamente sobre histórias em quadrinhos, e em escolas de quadrinhos, sendo 
a mais prestigiada a Escola de Quadrinhos de Malmö, da qual saíram quadrinistas que atualmente fazem sucesso dentro e fora da Suécia.

Na Suécia, é notável a participação das mulheres na indústria dos quadrinhos, principalmente a partir da primeira década do século XXI. Esta participação se deve, em parte, pela política adotada pelo governo sueco a partir dos anos de 1970, com o objetivo de aumentar a participação das mulheres no mercado de trabalho e combater o preconceito de gênero. Houve também a influência do movimento feminista, que, como veremos ao longo do artigo, encontrou nos quadrinhos um veículo para retratar as perspectivas das mulheres, compartilhar traumas privados, abordar temas tabus, explorar a sexualidade ou desafiar papéis de gênero.

As histórias em quadrinhos, independentemente da tipologia (terror, humor, aventura, etc), podem ser tratadas como "tecnologias de gênero", conceito cunhado por Teresa de Lauretis para quem o gênero é um produto de diferentes tecnologias sociais, tais como internet, rádio, televisão, cinema e jornais, que formam discursos, constroem e desconstroem a forma como homens e mulheres se percebem como tal (LAURETIS, 1994: 228). Os quadrinhos produzem discursos ${ }^{2}$ que podem ser considerados uma tecnologia de gênero.

Os vários tipos de quadrinhos, os de humor circulam amplamente em jornais e revistas, destacam-se como lugar privilegiado para se questionar o papel das mulheres na sociedade e expressar posicionamentos políticos. Esses quadrinhos ganharam o gosto do público sueco ao trazerem um discurso contundente acerca do papel de homens e mulheres na sociedade. Uma característica [da produção] de quadrinhos da Suécia é a presença de [uma produção] fortemente politizada e influenciada pelo feminismo; a análise dos quadrinhos de humor feminista nos permite compreender a dinâmica social daquele país que pode, ao mesmo tempo, ser tão distante e tão próxima daquela que vivenciamos no Brasil. Mesmo quando o feminismo não aparece como o foco central da narrativa, esta muitas vezes se constrói a partir da sua perspectiva, como veremos mais adiante.

\section{A explosão dos quadrinhos suecos no final do século XX}

No ocidente, os quadrinhos suecos possuem uma tradição antiga, comparável a de países como Suíça, França e Estados Unidos. Já no século XIX, eles eram utilizados como recurso pedagógico naquele país, inicialmente por uma mulher, Eva Ottilia

1 A Comic Art School localizada na cidade de Malmö é umas das mais importantes escolas voltadas para a formação de profissionais ligados à área dos quadrinhos na Suécia. Seu corpo docente é formado por quadrinistas profissionais que já possuem o nome consolidado na cena dos quadrinhos suecos. De lá saíram artistas, editores e roteiristas que ganharam fama nacional e internacional. A escola oferece três cursos com a duração de um ano cada: o curso básico para a criação de quadrinhos; um curso voltado para a produção de quadrinhos independentes; um curso voltado apenas para artistas profissionais com projetos avançados. Além das disciplinas voltadas para a produção de quadrinhos, a escola ainda fornece orientação aos alunos de como se inserir no mercado e promover seu trabalho.

2 A categoria discurso é aqui tratada como "palavra em movimento, prática de linguagem" que, segundo, Eni Olrlandi produz sentidos. (ORLANDI, 2009: p. 15). 
Adelborg, que em 1882 publicou sua primeira ilustração em um livro e na década de 189o, voltada ao público infantil (STRÖMBERG, 2010: 25). Em 1896, a mesma autora publicou a história em quadrinhos Pelle Snygg och barnen i Snaskeby (Pelle Elegante e crianças em Snaskeby), onde ensinava noções de higiene para crianças (JONSSON, GREFVE, 2015: 17).

Atualmente, a produção sueca diferencia-se da franco-belga eda estadunidense, para citar alguns países ocidentais no quais se concentra a atenção da maior parte dos pesquisadores da área, por um aspecto: a Suécia é um dos poucos países onde existe um equilíbrio nos números de homens e mulheres na indústria dos quadrinhos. Isso se deve ao fato das editoras terem criado cotas para mulheres, o que possibilitou que muitas autoras pudessem publicar seus quadrinhos no formato álbum. A iniciativa partiu de uma das maiores editoras do país, a Galago, que em 2009, decidiu publicar igualmente homens e mulheres, ou seja, 50\% dos quadrinhos da editora passaram a ser assinados por mulheres. (LINDBERG, 2016: o6).

A criação de cotas não apenas deu visibilidade para as mulheres como ampliou consideravelmente o público leitor, favorecendo as vendas e, em contrapartida, aumentando os lucros das editoras que acreditaram nas políticas de igualdade de gênero, que começou a ser implementada nos anos de 1970 e reforçadas no final da década de 1990 com a criação, em 1998, da Secretaria Sueca de Pesquisa de Gênero, com o objetivo de fortalecer e disseminar o conhecimento e a pesquisa relacionados à igualdade de gênero. Em 2005, formou-se Feministiskt Initiativ, um partido político feminista e o governo atual, uma coalizão dos Sociais Democratas e do Partido Verde, declarou-se "o primeiro governo feminista do mundo" (SANDSTRÖM , 2017, p. 12). Em 2015, de dez autores de quadrinhos suecos destacados por Alexandra Sundqvist em uma publicação do The Swedish Arts Council ${ }^{3}$, apenas três eram homens.

Embora os homens ainda sejam a maioria entre editores, professores e críticos de quadrinhos, este número vem sendo equilibrado a cada ano devido, também, à ação de coletivos de quadrinhos feministas que foram formados na Suécia por volta de 2005, como Polly Darton e o Dotterbolaget. O objetivo desses coletivos de quadrinhos é funcionar como uma rede que possibilita a publicação de quadrinhos feitos por mulheres e pessoas trans, incentivando quadrinistas a trabalharem juntas e apoiar umas às outras. Entre suas muitas atividades, eles publicam fanzines e álbuns conjuntos (LINDBERG, 2016: o6). Destes coletivos, o que mais se destaca na Suécia é o Dotterbolaget, cuja militância feminista teve grande importância para reforçar a presença feminina na cena dos quadrinhos suecos. Segundo Jeanette Sundhall,

(...) os coletivos ativistas estão tentando moldar o futuro dos quadrinhos à sua maneira. Um dos maiores é Dotterbolaget, um coletivo de mulheres trans e separatistas de quadrinhos que comemoraram seu $10^{\circ}$ aniversário no ano passado. Seus objetivos são trabalhar contra as estruturas patriarcais que acham

3 O Swedish Arts Council é um órgão do Ministério da Cultura da Suécia, cuja tarefa é promover o desenvolvimento cultural e o acesso, com base nos objetivos da política cultural nacional. O Conselho consegue isso alocando e monitorando o financiamento estatal, juntamente com outras atividades promocionais. 
evidente no meio dos quadrinhos a apoiar as mulheres e pessoas trans envolvidas nessa área. Eles realizam exposições, oferecem oficinas e publicam fanzines e quadrinhos (SUNDHALL, 2016: 78. Tradução da autora). ${ }^{4}$

Cabe ainda citar o status cultural conquistado pelas histórias em quadrinhos naquele país na última década. Na Suécia, as histórias em quadrinhos aparecem em programas de rádio e de televisão em horário nobre. Foram adaptadas para teatro e cinema e são avaliadas por críticos literários. Muitos quadrinistas, inclusive, já foram agraciados com prêmios literários pela riqueza e profundidade de sua obra, e entre eles muitas mulheres que fazem quadrinhos feministas. Os suecos desafiam a regra geral da indústria dos quadrinhos no ocidente ao dar importância às mulheres como produtoras e pela forma como tratam os quadrinhos. As histórias em quadrinhos de humor têm um importante papel nessa revolução cultural, especialmente o humor das mulheres, que iremos conhecer nas próximas páginas.

A indústria dos quadrinhos na Suécia não seguiu a tendência de outros países da Europa como França e Bélgica, onde no final dos anos de 1950 os quadrinhos começaram a se firmar como mídia e, posteriormente, como uma forma de arte (MAZUR, 2014: 16). No caso da Suécia, os quadrinhos foram conquistando um status maior na sociedade, cerca de três décadas depois, justamente por conta do avanço das conquistas feministas. As mulheres encontraram na arte e na mídia espaços para exprimir seus anseios com relação à sociedade sueca e, principalmente, criticar aquilo que ainda precisava ser mudado. Uma das influências neste campo foram os quadrinhos de Claire Bretécher, que começaram a ser publicados na Suécia a partir da década de 1980.

A francesa Claire Bretécher iniciou sua carreira como cartunista em 1963, com a revista Le Facteur Rhésus e atingiu o sucesso em 1969, com a personagem Cellulite, traduzida em sueco como Cellulis, publicada originalmente pela revista Pilote. Cellulite é um dos primeiros quadrinhos de humor da França a ter como heroína uma mulher independente, uma princesa que se cansou de esperar por um príncipe encantado. Embora ambientada na Idade Média, a história em quadrinhos faz uma crítica contemporânea à sociedade patriarcal5 francesa.

Sobre o feminismo de Bretécher, a pesquisadora Mira Falardeau escreveu: "Ela zomba de todas as falhas contemporâneas com seu telescópio feminista, que não é desprovido de uma certa ternura" (FALARDEAU, 2014: 1968. Tradução da autora)6 . Na Suécia, a HQ mais popular de Bretécher foi Les frustres, traduzido em sueco

4 "(...) the activistic collectives that are currently trying to shape the future of comics in their own way. One of the biggest is Dotterbolaget, a trans and women separatist comic collective that celebrated their oth year anniversary last year. Their aims are to work against the patriarchal structures they think are evident in the comic world and to support the women and trans people involved in this area. They create exhibitions, hold workshops and publish fanzines and comic books"

5 A categoria "patriarcado" é amplamente utilizada pelas autoras feministas suecas, seja nos quadrinhos, seja em boa parte da produção acadêmica utilizada neste artigo. Ela é aqui utilizada para designar "uma formação social em que os homens detêm o poder, ou ainda, mais simplesmente, o poder é dos homens" (DELPHY, 2009: 173).

6 "Elle se moque de tous les travers contemporains avec sa lunette feministe, non denuée d'une certe tendresse." 
como De frustrerade, uma série de crônicas em quadrinhos de homens e mulheres que confrontados com problemas cotidianos acabam refletindo sobre questões como educação, vida conjugal, emancipação das mulheres, crises existenciais, política, etc. Claire Bretécher abriu o caminho para a produção de quadrinhos na qual as mulheres exibiam sua capacidade detalhista de observação fazendo humor a partir da grosseria (WIHLKE, acesso em: 22 mai. 2018).

No início do século XIX, fanzines, produções independentes e as webcomics abriram espaço para que um número cada vez maior de autores, amadores e profissionais, encontrassem um público que desejava algo mais do que os quadrinhos mainstream7 ${ }^{7}$, veiculados pelas grandes editoras. Embora a produção de quadrinhos feministas não fosse uma novidade, no final dos anos de 1990, os temas que passaram a circular nessas produções passaram a ser marcados pela diversidade, pela necessidade de enxergar as mulheres em sua pluralidade. Na Suécia, no “(...) final da década de 1990, a comunidade de zines feministas suecas começou a florescer e, no início dos anos 2000, as redes de zines começaram a se mover em direção a uma comunidade de zines principalmente nacional, com sua característica distinta sueca" (SANDSTRÖM, 2017: 14. Tradução da autora) ${ }^{8}$.

Enquanto no resto do mundo houve uma fragmentação do movimento feminista, que se dividiu em várias correntes, na Suécia ocorreu o contrário. O conflito entre a nova e a velha geração de feministas levou ao fortalecimento da ideia de sororidade (Sisterhood) ${ }^{9}$ o que fez com que, mesmo havendo tendências diferentes, o movimento feminista saísse fortalecido. Ou seja, as feministas suecas, mesmo que com ideias ideologicamente divergentes assumem a necessidade de união contra o patriarcado, deixando de lado suas diferenças para manter o movimento fortalecido (SANDSTRÖM, 2017: 17).

E é justamente o humor feminista que domina a cena dos quadrinhos na Suécia, através de tiras publicadas em jornais ou em coletâneas. Quadrinhos feministas, satíricos e políticos são uma das leituras preferidas dos suecos. Uma segunda geração de quadrinistas feministas entrou em cena nos últimos dez anos com obras que conquistaram muitos leitores, fazendo com que fossem publicadas por grandes editoras suecas e o que antes eram fanzines feministas que circulavam de forma limitada passaram a ser publicados como álbum e a ocupar as prateleiras da grandes e tradicionais livrarias suecas. Segundo Stina Sandström,

As histórias em quadrinhos são agora reconhecidas como uma forma literária legítima que tem o potencial de lidar com questões que cercam a desigualdade de gênero. Na cultura sueca de quadrinhos em particular, essa forma de entretenimento tem

7 Quadrinhos mainstream são histórias em quadrinhos tradicionalmente produzidas de forma industrial, em uma linha de produção (MAZUR, DANNER, 2014: p. 09).

8 "By the late 1990s, the Swedish feminist zine community started to flourish and by the early 2000 zine networks started moving towards a principally national zine community with its distinctive Swedish characteristics."

9 O termo sisterhood (sororidade) foi proposto no final dos anos 1960 pela escritora norte-americana Kate Millet, para se referir à união de todas as mulheres "sem fazer distinção de classes sociais ou origem étnica. 
sido cada vez mais cooptada para enfrentar o desequilíbrio social, atuando como uma arena de debate e discussão (SANDSTRÖM, 2017: 05. Tradução da autora) ${ }^{10}$.

Para Fredrick Stromberg, apesar da história das mulheres nos quadrinhos suecos não ser recente, nos últimos dez anos a entrada de uma nova geração de mulheres na cena dos quadrinhos suecos provocou uma série de mudanças que levaram esta mídia a outro patamar. Segundo o pesquisador, as mulheres estão liderando o mercado de quadrinhos na Suécia no momento. Por um tempo, isso foi principalmente através de quadrinhos políticos, feministas, mas hoje em dia é em todos os tipos de gêneros ${ }^{11}$. Para Stromberg esse fenômeno é resultado do amplo debate acerca da igualdade de gênero que vem ocorrendo no país há algumas décadas.

(...) foi preciso até o século 21 para que as mulheres entrassem completamente no negócio de quadrinhos e desafiasse o domínio masculino. Esse nãoé, obviamente, um fenômeno insular, mas um sintoma de um debate público ativo sobre igualdade na sociedade sueca por algum tempo. Olhando para a década anterior do século 21, é evidente que as artistas femininas dominaram os quadrinhos suecos, e que há muitos quadrinhos diferentes, interessantes e instigantes sendo feitos agora (STROMBERG, 2010: p. 97. Tradução da autora) ${ }^{12}$.

Feita a devida contextualização, partiremos agora para a análise do humor feminista nos quadrinhos suecos. Para tanto, faremos a análise de uma parte da obra de três autoras suecas da nova geração de quadrinistas, Nina Hemmingsson, Malin Biller e Liv Strömquist, que conquistaram o mercado sueco e são, inclusive, publicadas no exterior. Três mulheres, três estilos diferentes, que guardam características dos quadrinhos feministas e do humor sueco que, pode-se dizer, é um humor feito partindo da ideia de que os quadrinhos possuem uma função social bem clara: de questionar, denunciar e apontar as máculas de uma sociedade que busca a igualdade, mas que ainda precisa superar muitos obstáculos.

\footnotetext{
10 Comics are now acknowledged as a legitimate literary form that has the potential to deal with issues surrounding gender inequality. In Swedish comic culture in particular, this form of entertainment has been increasingly coopted to confront to social imbalance, acting as an arena for debate and discussion

11 Entrevista realizada pela autora com o pesquisador, historiador dos quadrinhos e jornalista Fredrick Stromberg, no dia 23 de abril de 2017 .

12 Even so, it took until the $21^{\text {st }}$ century for women to fully enter the comics business and challenge the male dominance, This is of course not an insular phenomenon but a symptom of an active public debate about equality that has been going on in Swedish society for quite some time. Looking back at the forst decade of the $21^{\mathrm{st}}$ century, it is evident that female artists have dominated Swedish comics, and that there are a lot of different, interesting, thought-provoking comics being made right now.
} 


\section{O humor feminista das quadrinistas suecas}

Antes de partir diretamente para a análise do humor nos quadrinhos feministas suecos, cabe aqui fazer uma pequena introdução sobre a questão do humor das mulheres. Embora ele não tenha necessariamente que ser feminista, pois há quadrinistas que trabalham com o humor, com a sátira, sem ter como foco a agenda feminista, e mesmo recorrendo a formas de humor semelhantes ao humor masculino, vai ser o humor feminista que predominará na maior parte da produção de quadrinhos e outras formas de narrativa humorística. Isso porque o humor feminista tende a atacar as formas estereotipadas das mulheres, presentes na literatura, no cinema, nas artes em geral e, claro, na própria sociedade.

Da mesma forma como acontece em outros campos culturais, as mulheres que fazem humor estão invisibilizadas. Por séculos se negou às mulheres o humor ou a capacidade de compreender o humor masculino. A elas também foi negada a capacidade de fazer humor como se apenas os homens tivessem a capacidade de fazer rir e como se o humor se circunscrevesse a uma prática única sob controle e monopólio masculino. No entanto, há pluralidade no discurso humorístico que é marcado pela diversidade e possui diferentes significados em diferentes contextos. Sobre a exclusão do humor das mulheres e das mulheres que fazem humor pela história, Mira Farlardeau afirmou em seu livro Femmes et humour

Quando falamos de humor em geral, estamos falando do humor dos homens. O gênero masculino cruzando o gênero feminino, não nos incomodamos, nos vários tratados que abordam a filosofia do humor, em distinguir o público, mais do que fazer uma separação de acordo com o sexo dos criadores: a história é extremamente mesquinha em relação ao humor das mulheres (FALARDEAU, 2014: 224.Tradução da autora) ${ }^{13}$.

O humor é subversivo, é por vezes agressivo e considerado uma forma de expressão da inteligência do homem. Sim, do homem, não mulher. Na sociedade patriarcal, reconhecer o humor da mulher é dotá-la de sagacidade, de inteligência e, sobretudo, permitir que ela seja subversiva. Ao permitir a subversão da mulher, os homens estão colocando em risco a própria ordem patriarcal e com ela a dominação masculina. Negar o humor das mulheres é mantê-las impotentes face à suposta superioridade masculina.

O humorista vai de encontro aos valores publicamente aceitos da cultura, ele mostra que os pés dos santos são de barro, diz que não apenas o imperador está nu, mas também estão o político, o

13 Lorsque l'on parle de l'humour en général, on parle donc en fait de l'humour des hommes. La genre masculin recoupant la genre fémin, on ne prenda pas la peine, dans les divers traités abordant la philosophie de l'humour, de distinguer les publics, pas plus que de faire une séparation selon les sexe des créateurs: l'histoire est extrêmement avare en ce qui concerne les femmes humorites. 
piedoso, o pomposo. Para as mulheres, tomar tal atitude significa quebrar as regras da posição pacífica e subordinada, que lhes foi conferida por séculos de tradição patriarcal, e revelar as vergonhas, hipocrisias e incongruências da cultura dominante. Ser uma mulher e humorista é confrontar e subverter o próprio poder que mantém a mulher impotente e, ao mesmo tempo, correr o risco de confrontar justamente aqueles de quem ela é dependente (SILVA, 2015: 61).

Como veremos a seguir, o humor é utilizado como forma específica de expressão das mulheres em inúmeras questões que não se limitam apenas à agenda feminista. Os quadrinhos feministas, em sua essência, tornaram-se "algo mais". Sua estética difere muito dos quadrinhos tradicionais, assinados pelos homens. As formas pelas quais as mulheres se representam e representam os homens são outra característica dos quadrinhos suecos, como veremos mais adiante. Pode-se dizer que os quadrinhos feministas se apropriam de um meio de comunicação tradicional a partir de uma perspectiva diferente (BROSTRÖM, acesso em: 22 mai. 2018). Segundo Alba Valéria Tinoco Alves Silva,

para que o humor das mulheres adquira reconhecimento e abrangência, é necessário que ela fale de coisas sérias. Não admira, portanto, que muito do humor feminino europeu e americano aconteça no rastro dos movimentos feministas. A luta pelo voto e pela igualdade de direitos dá à mulher um poder sem precedentes na história. E um certo senso de poder é necessário para a criação do humor, que, por sua vez, gera mais poder para quem o faz (SILVA, 2015: 79).

E este poder é bem visível nas produções cômicas suecas, como iremos ver a seguir. A partir da análise de três quadrinistas suecas selecionadas para este artigo: Nina Hemmingsson, especificamente o álbum Jag är dim Flick vän nu, cuja tradução aproximada é Eu sou sua namorada agora, as tiras cômicas de Malin Biller e o álbum A origem do mundo, de Liv Strömquist, que foi recentemente publicado no Brasil pela Companhia das Letras e cujo nome original é Kunskapens frukt. Elas fazem sucesso falando sobre suas experiências, sobre feminismo, política, meio ambiente e temas de interesse geral do público sueco, alternando por vezes entre humor e drama. 

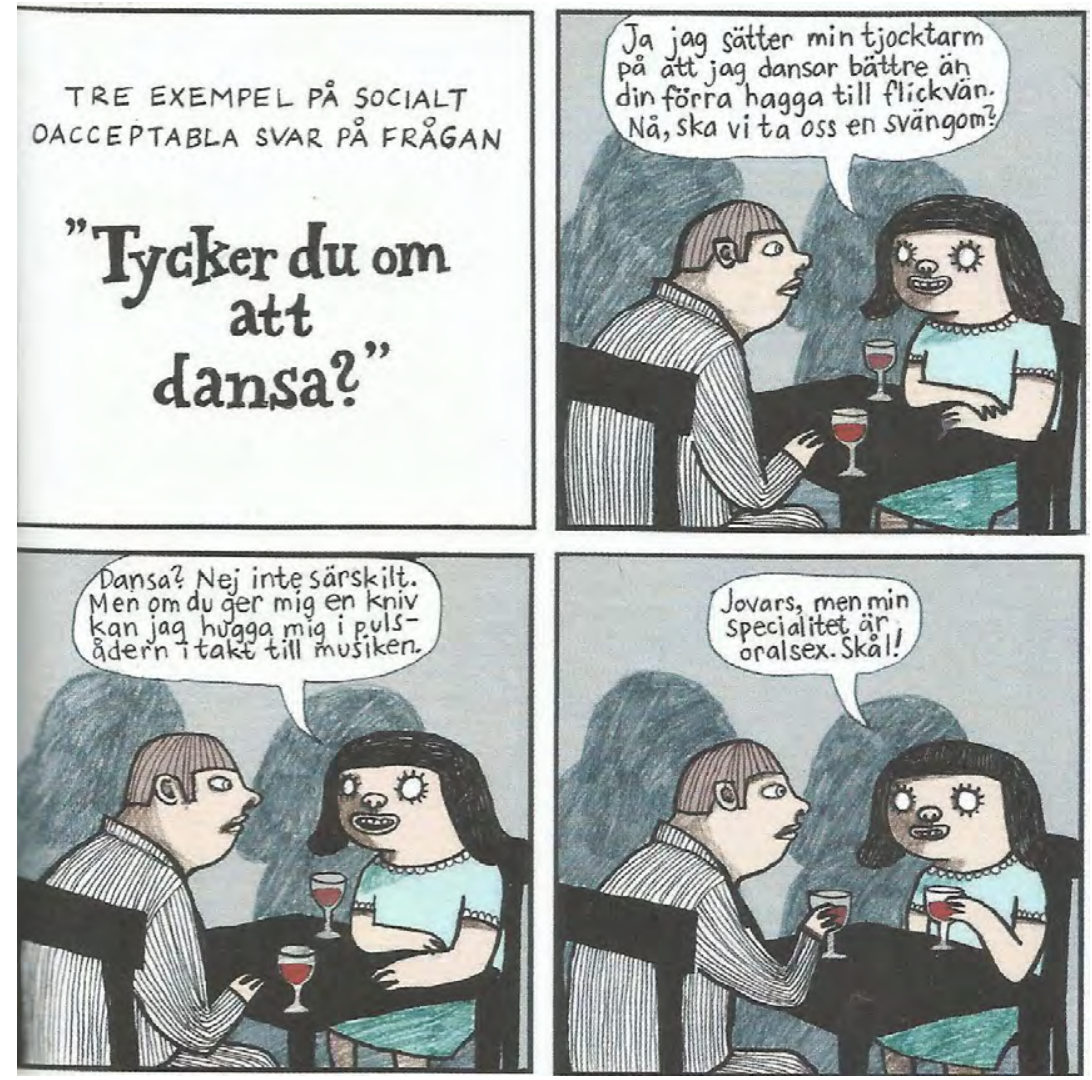

Figura 2 - HQ retirada do livro Jag är dim Flick vän nu (Eu sou sua namorada) - Quadro 1 - Três exemplos para respostas socialmente inaceitáveis para a pergunta: Você gosta de dançar? /Quadro 2 - Sim, eu coloco meu intestino para dançar melhor do que sua horrível ex-namorada. Não, vamos dar uns passos de dança? /Quadro 3 - Dançar? Não exatamente.

Mas se você me der uma faca eu posso cortar meus pulsos no mesmo ritmo da música./

Quadro 4 - Sim, mas a minha especialidade é sexo oral. Tim tim! (tradução Ricardo Gonça lves) (c) Nina Hemmingsson

Nina Hemmingsson é considerada umas das pioneiras da nova geração de quadrinistas suecas. Nascida em 30 de novembro de 1971, seus primeiros quadrinhos foram publicados em 2004 pela Kartago, empresa na qual assumiu o posto de editora em 2017. Hemmingsson tem formação em artes pela Academia de Belas Artes de Trondheim, na Noruega (SUNDQVIST, 2015: 10). Os quadrinhos vieram mais tarde, assim como o reconhecimento da sua obra que inovou os padrões estéticos e narrativos dos quadrinhos suecos tornando-se uma das quadrinistas mais bem sucedidas daquele país.

Seus quadrinhos são curtos, muitas vezes apenas com um ou dois quadros e podem ser caracterizados por diálogos marcados por uma sátira afiada, que desafia os padrões da sociedade patriarcal chegando mesmo a uma grosseria obscena, possivelmente chocante para os padrões brasileiros, mas que agrada aos leitores 
suecos. Em seus quadrinhos, ela critica normas sociais, reexamina as noções de amor, de sexualidade e os papéis de gênero. Eu seu álbum Jag är dim Flick vän nu (Eu sou sua namorada agora), Nina Hemmingsson se autorrepresenta a partir da personagem principal de suas tiras, uma mulher morena, de olhos sem pupilas e com profundas olheiras. Seu corpo é roliço e sua boca se assemelha a uma vulva.

A questão da autorrepresentação está presente em muitos quadrinhos produzidos por mulheres, seja no humor ou em outros gêneros. Lauretes afirma que as mídias, assim como o cinema, trazem representações e autorrepresentações da sexualidade feminina e masculina, nas quais geralmente prevalecem o olhar masculino devido, segundo a autora, à visão androgênica ${ }^{14}$ da sociedade (LAURETIS, 1994: 223). Mas no caso dos quadrinhos suecos, esta visão é desconstruída e, notadamente nos quadrinhos de Nina Hemmingsson, a sexualidade feminina não é necessariamente uma projeção da masculina.

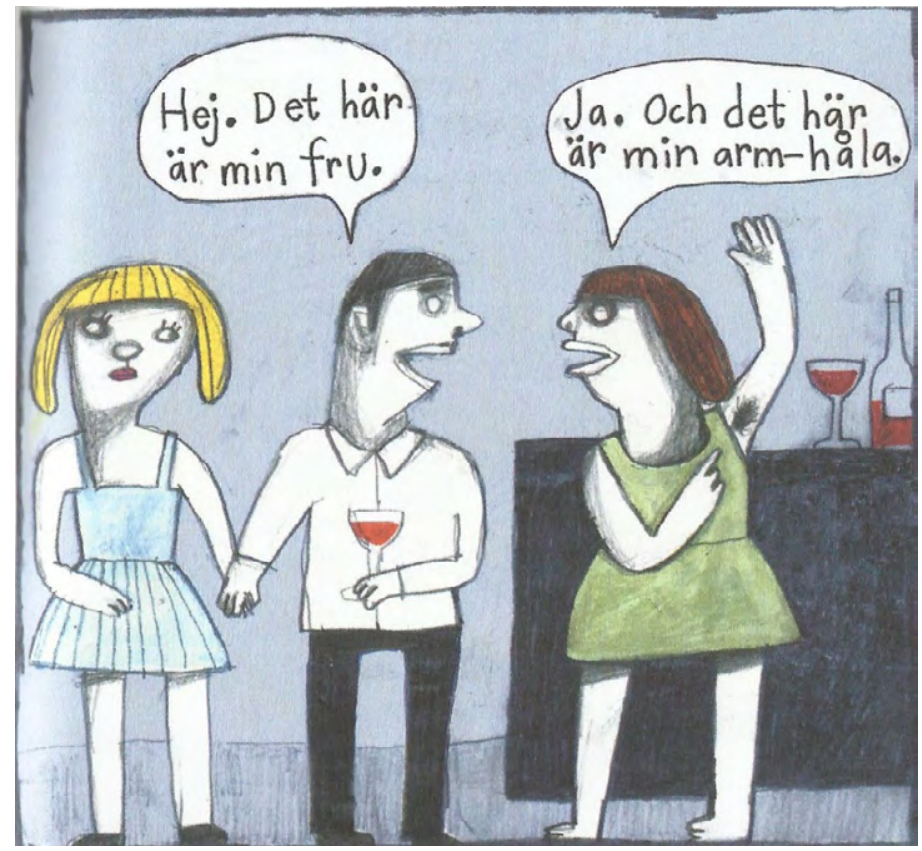

Figura 3 - HQ retirada do livro Jag är dim Flick vän nu (Eu sou sua namorada) - Oi, esta é minha esposa/ - Sim. E essa é a minha axila (tradução da autora). (c) Nina Hemmingsson.

O estilo de Nina Hemmingsson é expressionista, focados nos estados psicológicos dos personagens. Ela não concebe personagens esteticamente perfeitos, embora não lhe falte habilidade artística para isso, mas propositalmente deformes. São mulheres francas e grosseiras, jovens e idosas. Essa autora transfere para suas personagens traços típicos do comportamento masculino e estabelece a partir daí sua crítica à sociedade patriarcal. O objetivo do seu humor é principalmente chocar e fazer o leitor questionar as relações de gênero e até mesmo o comportamento sexual de homens e mulheres.

$14 \mathrm{O}$ androcentrismo é a tendência quase universal de se reduzir a raça humana ao termo "o homem". O seu oposto, relacionando-o com a mulher, designa-se por ginocentrismo. 
Mais comum nas histórias em quadrinhos feministas suecas do que essas figuras sexualmente ambivalentes são personagens que podem ser identificados como grotescos femininos. O corpo grotesco feminino; nua, aberta, obesa ou deformada é uma reação contra, e uma alternativa ao corpo feminino hegemônico "saudável" e "inatingível" como representado pela cultura de consumo. Além disso, ogrotesco feminino joga com as expectativas das identidades heterossexuais de gênero binário; o masculino e o feminino, invertendo-os e exagerando-os (SANDSTRÖM, 2017:25 - Tradução da autora $)^{15}$.

Outro traço característico de sua obra é a despreocupação com a sequência narrativa. Não há um roteiro definido ou uma lógica a ser seguida pelo leitor. Em uma página de seu álbum, por exemplo, temos um monólogo (Figura 2) no qual uma personagem, a autorrepresentação da autora, durante o encontro com um homem, oferece três opções de respostas absurdas para a pergunta "Você quer dançar?". A ideia é chocar o leitor com respostas que uma mulher nunca daria a um homem, rompendo assim com o comportamento normatizado imposto à figura feminina em situação semelhante. Já em outra história em quadrinhos (Figura 3), temos um diálogo entre uma mulher e um homem que lhe apresenta a "esposa". A mulher, em resposta, lhe apresenta sua axila como uma forma de crítica à representação da mulher como objeto de posse do homem.

Estes quadrinhos de humor, ácidos e grosseiros, foram responsáveis pela elevação dos status cultural e social das histórias em quadrinhos na Suécia e Nina Hemmingsson por esse processo inspirou muitas outras quadrinistas a inovarem em suas produções, a criarem quadrinhos cômicos e em outros estilos que criticam e apontam as mazelas da sociedade sueca que, apesar de todos o esforço feito pelo governo desde os anos de 1970, ainda é profundamente patriarcal.

\section{2 - Malin Biller}

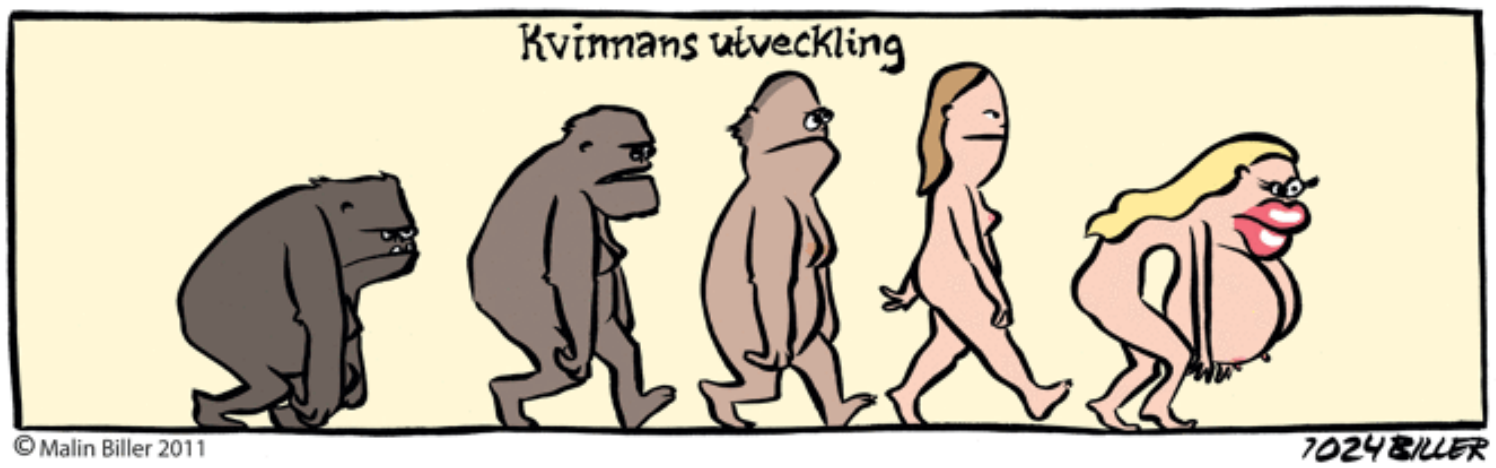

Figura 04 - Tira cujo título é O desenvolvimento (evolução) da mulher @Malin Biller.

15 More common in Swedish feminist comics than these sexually ambivalent figures are characters that can be identified as female grotesques. The female grotesque body; naked, open, obese or deformed is a reaction against, and an alternative to, the hegemonic 'wholesome' and 'unachievable' female body as represented by consumer culture. Furthermore the female grotesque plays with the expectations of heterosexual binary gender identities; the masculine and the feminine by inverting and exaggerating them. 
Malin Biller é uma quadrinista sueca que vem se destacando nos últimos anos. Nascida em 1979, em Helsingborg, cidade portuária localizada ao sul da Suécia, é a mais jovem do grupo que está sendo analisado. Biller é uma quadrinista que, pela sua própria trajetória de vida, transita entre o drama e o humor, sendo que este último é bem marcante na sua obra. Começou a produzir quadrinhos aos 22 anos, quando entrou para a Escola de Quadrinhos de Malmö (NOGUEIRA, 2017: o8). Ficou famosa por sua série de humor, chamada Biller, cujas tiras foram reunidas em um álbum e publicadas em 2005 pela editora Collage. Coleciona prêmios desde que começou a publicar seus quadrinhos, em 2003.

Com uma história familiar complicada, na qual foi vitima de um pai alcoólatra e abusivo, Malin Biller encontrou no humor uma forma de defesa e, mais tarde, ele acabou se convertendo em instrumento para que ela pudesse expressar suas opiniões acerca da sociedade sueca e denunciar, entre outras coisas o culto ao corpo perfeito e a gordofobia ${ }^{16}$, tanto que uma das características de seus personagens, via de regra, é a de estarem acima do peso. Suas tiras foram publicadas em vários jornais suecos com uma grande receptividade.

Apesar de ser uma artista que transita porvários gêneros dentro dos quadrinhos, o humor é o lugar em que ela se sente mais a vontade. Suas tiras mostram situações cotidianas de forma engraçada e, ao mesmo tempo, fazem uma crítica aos costumes, ao papel da mulher na sociedade, ao consumismo e à preocupação exagerada com a aparência feminina. Muitos dos seus quadrinhos de humor são baseados em suas experiências. Suas personagens femininas podem ser consideradas tão subversivas como as de Nina Hemmingsson, pois podem apresentar características consideradas masculinas. São meninas que agem como meninos: falam palavrão, são gulosas, obesas, grosseiras e adoram sexo.

Na figura 04, por exemplo, com sua tira "kvinnans utveckling", que pode ser traduzida como "evolução da mulher", Malin Biller critica a sociedade por estereotipar o corpo feminino a partir de padrões impostos principalmente pela mídia (as próteses enormes nos seios, o preenchimento excessivo dos lábios, etc.), assim como os exageros que isso pode acarretar. Ela também mostra como as mulheres cedem às expectativas sociais e se curvam para serem aceitas, admiradas e vistas como bonitas. Já em outra imagem (figura 5) ela mostra uma mulher em busca de sexo, imaginando um supermercado no qual há uma "liquidação de homens" e maliciosamente comenta que "pretende levar dois para casa", para aproveitar o fim de semana. O humor contido nesses dois exemplos revela a sagacidade da autora, que deixa bem claras suas intenções ao brincar com padrões de comportamento de consumo. Da mesma forma, ela apresenta outro exemplo de inversão dos papéis de gênero ao colocar em cena a libido feminina de forma espontânea e bem humorada.

A autora também recorre muitas vezes à autorrepresentação e mesmo à autobiografia. Biller parte da sua experiência cotidiana para satirizar comportamentos. Um caso de assédio no transporte público, um homem urinando na parada do ônibus, um comportamento impróprio no supermercado, uma criança malcriada 16 Gordofobia significa aversão a pessoas gordas. 
num parque. Tudo serve como matéria-prima para Biller criar suas tiras. Em poucos quadros, a autora faz uma crônica da vida social sueca e aponta aquilo que ainda precisa ser melhorado.

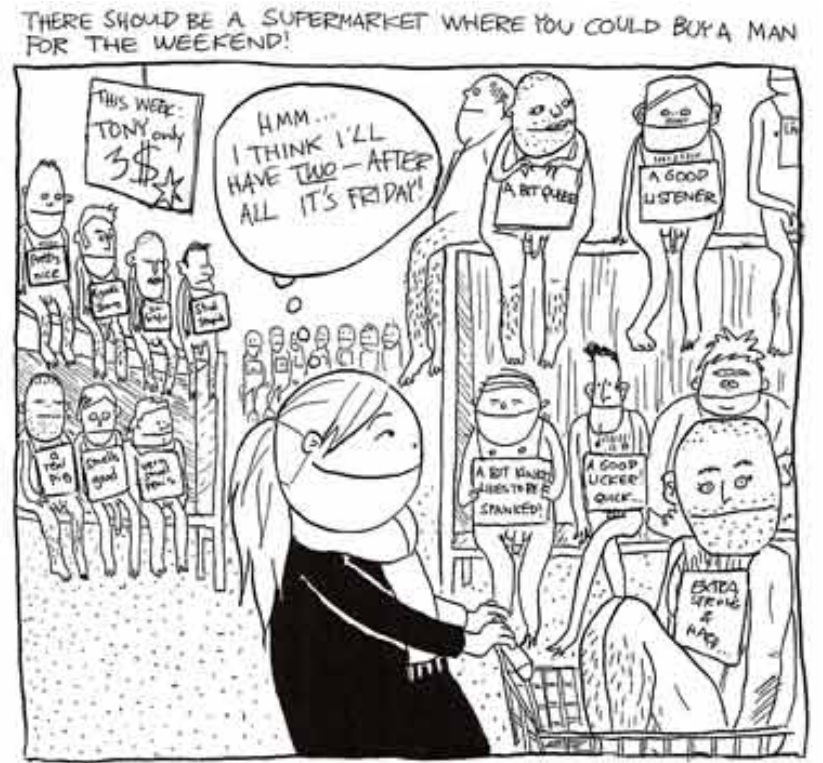

Figura 05 - A tira mostra a personagem de Biller imaginando como seria ir a um supermercado comprar "um homem" para o fim de semana: - Deveria haver um supermercado onde você pudesse comprar um homem para o final de semana / - "Hmm...

Eu acho que vou levar dois - afinal é sexta-feira” (Tradução da autora) @ Malin Biller.

Esta postura feminista, que critica abertamente os estereótipos femininos e o machismo na sociedade, revela os limites da igualdade de gênero na Suécia. A autora eventualmente recebe críticas ao seu trabalho, geralmente de homens mais velhos que, segundo ela, "não gostam de mulheres cartunistas com opinião forte" ${ }^{17}$. Mas, uma grande parcela dos leitores, principalmente dos jornais, não só aprovam como apreciam os quadrinhos feministas, prova disso é o fato de Malin Biller usufruir de uma situação privilegiada entre os quadrinistas suecos: ela se sustenta apenas com seu trabalho com quadrinhos.

E como começamos a falar sobre os limites da igualdade de gênero na Suécia, cabe abrir aqui um parênteses para chamar a atenção para um obstáculo que as mulheres suecas ainda lutam para ultrapassar. Embora elas atualmente desfrutem de uma situação privilegiada, se comparadas a profissionais de outros países ocidentais, com relação à sua participação no mercado dos quadrinhos, ainda recebem, em muitos casos, uma remuneração inferior à dos homens. Segundo a jornalista cultural, quadrinista e atualmente editora da Galago, Sofia Olsson, ainda existe uma grande disparidade entre o valor dos salários pagos a homens e mulheres. ${ }^{18}$ No entanto, esta

17 Entrevista com a quadrinista Malin Biller, realizada no dia 02 de dezembro de 2016.

18 Entrevista com a jornalista, editora e quadrinista Sofia Olsson, realizada em dia 03 de março de 2017. 
situação não invalida as conquistas obtidas neste campo na última década. Pelo contrário, ela tanto justifica a militância feminista também através dos quadrinhos como alimenta a criatividade das autoras que "fazem humor".

\section{3 - Liv Strömquist}

Liv Strömquist nasceu em Lund, em 1978. Assim como Malin Biller, começou a fazer quadrinhos já adulta, aos 23 anos de idade. Seu primeiro álbum, Hundra procent fett (Cem por cento de gordura) foi publicado em 2005. Sua formação não é em artes, mas em Ciências Políticas e seus quadrinhos giram principalmente em torno de questões sociopolíticas a partir de uma perspectiva feminista (STROMBERG, 2010: 97). Seu sucesso veio rapidamente, em 2006, com o álbum Einsteins fru (Esposa de Einstein). Liv Strömquist é considerada atualmente uma das quadrinistas mais influentes da Suécia (SUNDQVIST, 2015: 06).

Seus quadrinhos já foram publicados em vários países europeus e traduzidos para vários idiomas, tais como francês, português, inglês, holandês, dinamarquês, alemão e finlandês. Publicar em outros países tem sido a meta de muitos quadrinistas suecos, que costumam ter versões em inglês dos seus trabalhos, pois o público consumidor de quadrinhos na Suécia é pequeno se comparado a de outros países, visto que a população do país está na casa dos 10 milhões de habitantes. Além disso, existe o próprio limite imposto pelo idioma, falado apenas na Suécia.

A internacionalização da sua obra fez com que Liv Strömquist se coloque num patamar superior aos demais quadrinistas suecos, homens e mulheres. Seu álbum Kunskapens frukt, originalmente publicado na Suécia em 2014, foi traduzido para o português e publicado em 2018 no Brasil sob o título A Origem do Mundo - uma história cultural da vagina ou a vulva vs. o patriarcado, o que a tornou a primeira mulher quadrinista sueca a publicar no Brasil. Antes dela, apenas o quadrinista Kim Andersson, em 2017, havia publicado uma história em quadrinhos no Brasil, Alena, um quadrinho de terror cuja protagonista é uma jovem atormentada por fantasmas do passado. 


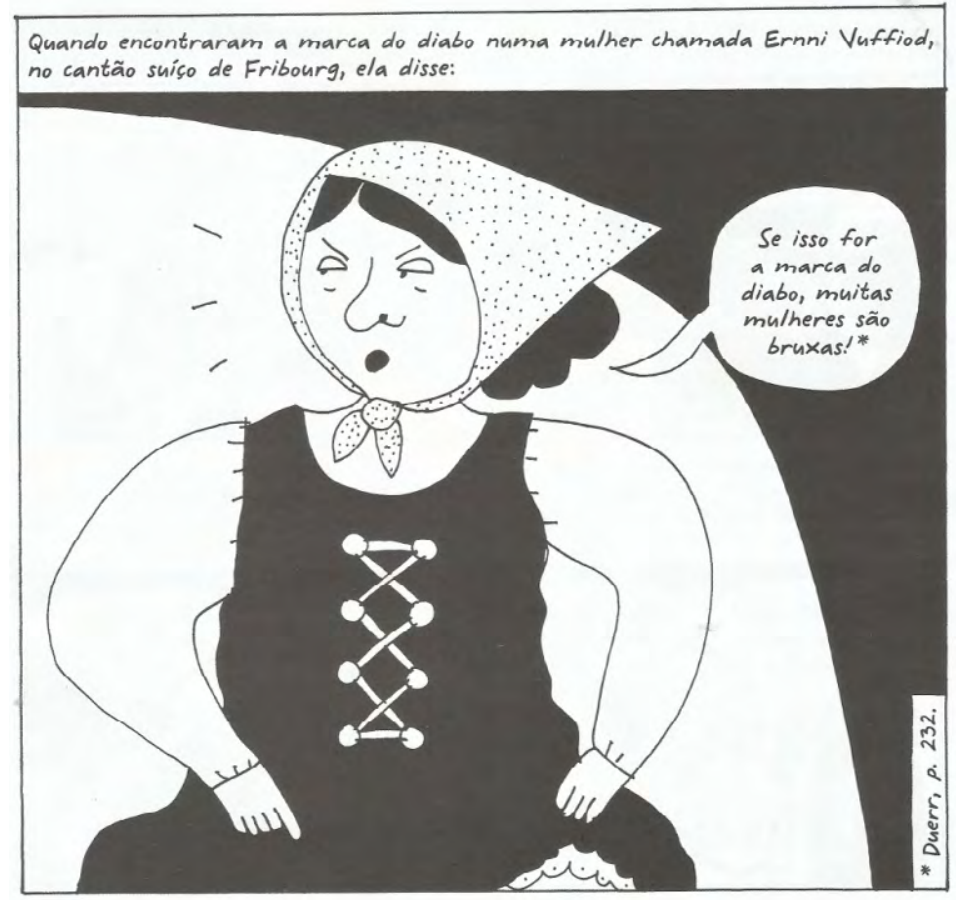

Figura o6 - Passagem do álbum A Origem do Mundo: uma história cultural da vagina ou a vulva vs. o patriarcado (Kunskapens frukt), em que a autora narra como durante os séculos XV - XVIII, durante a perseguição às bruxas tornou-se comum examinar os órgãos genitais das mulheres em busca de marcas de bruxaria @Liv Strömquist.

A Origem do Mundo é um dos quadrinhos mais populares de Strömquist, cuja narrativa traz uma síntese da história do patriarcado, analisado sob o prisma feminista, de forma bem humorada. É uma história em quadrinhos que se compromete a falar sobre as relações de gênero de forma divertida. O humor está presente em cada página, seguindo uma sequência narrativa que se divide em três partes: a história da vulva, a história do orgasmo feminino e a história da menstruação. Liv Strömquist demonstra, baseada em uma intensa pesquisa, as formas como a sociedade tratou o corpo e o sexo das mulheres ao longo da história.

Strömquist constrói sua crítica feminista na suposição de que é essencialmente o homem branco que escreveu a história dominante a partir de uma perspectiva patriarcal, muitas vezes excluindo mulheres. Strömquist se esforça para apresentar outras nuances e interpretações do passado que desafiam ideias recebidas sobre os fundamentos da sociedade. Sua mensagem se torna convincente, pois mantém suas representações próximas de fatos reais (LINDBERG, 2016: 18 - Tradução da autora). ${ }^{19}$

19 Strömquist builds her feminist critique on the assumption that it is essentially the white man who wrote the dominant story from a patriarchal perspective, often excluding women. Strömquist strives to present other shades and interpretations of the past that challenge received ideas about the foundations of society. Her message becomes convincing since she keeps her representations close to real facts. 
Sua obra é ao mesmo tempo informativa, didática e explicitamente feminista, denunciando a dominação masculina e a normatização das relações de gênero pela sociedade patriarcal. Ela conclama as mulheres a se levantarem contra a colonização do seu corpo e a perderem a vergonha de ser mulher, a vergonha da vulva, da sua sexualidade. Em sua história em quadrinhos, ela questiona comportamentos socialmente impostos e derruba mitos sobre a sexualidade e sobre o prazer sexual das mulheres. Cita exemplos da Bíblia e também de propagandas que circulam nos meios de comunicação, como a do uso do absorvente que, segundo ela, passa uma mensagem negativa sobre a menstruação e o corpo da mulher. Na figura o8, podemos ver um quadrinho na qual ela denunciou o fato de que as empresas que produzem absorventes femininos são responsáveis pela poluição da terra e dos mares, mas dão a entender que a menstruação é que é a verdadeira "sujeira".

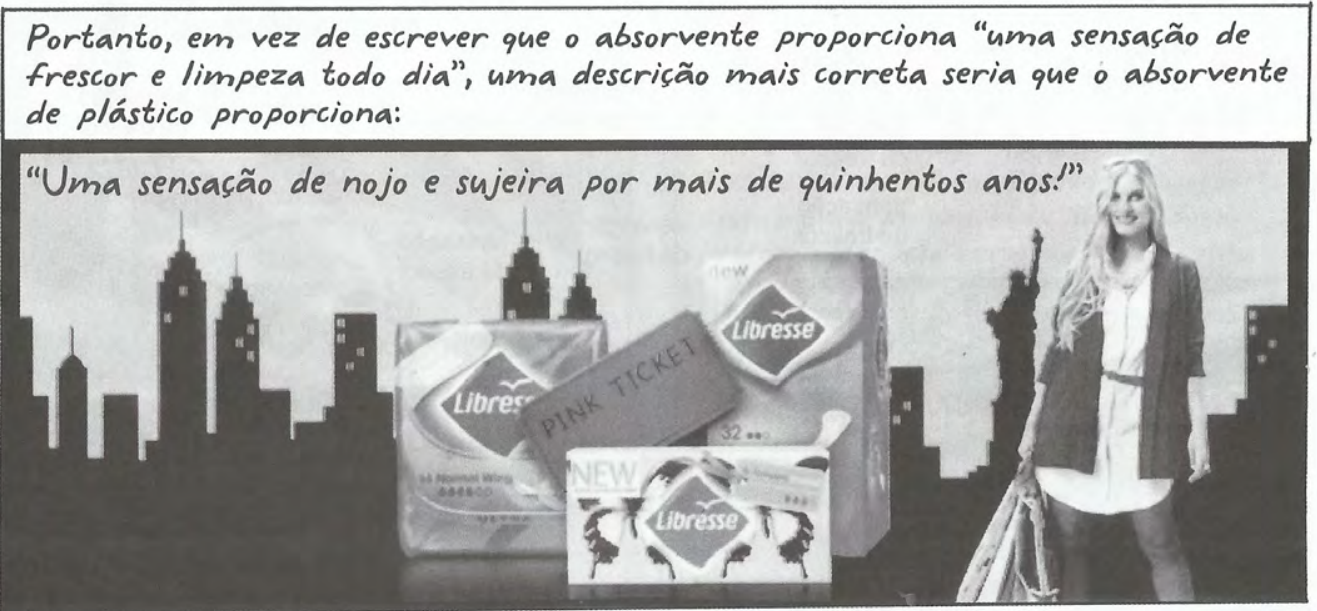

Figura o8 - Passagem do álbum A Origem do Mundo: uma história cultural da vagina ou a vulva vs. o patriarcado (Kunskapens frukt), no qual a autora faz uma crítica às empresas que produzem absorventes femininos @Liv Strömquist

A figura o8 também apresenta um dos recursos usados pela autora em suas obras, que é o da colagem, utilizada por muitos quadrinistas e também em fanzines. A técnica da colagem é um procedimento intertextual que "nos remete à citação, pois nela estão presentes os mesmos atos de retirada de um texto e inserção em outro" (FIGUEIREDO, 2013: 03), dando uma nova significação ao texto introduzido. A história em quadrinhos em si, usa técnicas bem simples e não se preocupa, assim como as outras autoras analisadas, com a perfeição estética. Em seu álbum, Liv Strömquist expõe contradições sociais e denuncia a dominação masculina sobre o corpo e o comportamento das mulheres em seus quadrinhos e constantemente usa do termo "patriarcado" ao se referir a esta dominação. 


\section{Considerações finais}

Segundo a pesquisadora sueca Ylva Lindberg (2014: 85), as séries de humor, invariavelmente, são produzidas para os homens e pelos homens, sendo que as mulheres aparecem apenas como objeto do humor masculino e não são convidadas a participarem como sujeito ativo. Os homens marginalizam as mulheres que fazem humor e as colocam em uma categoria separada. Mas, na Suécia, esta regra não se aplica. Lá as mulheres fazem humor com os homens.

Os quadrinhos de humor feministas suecos também demostram que as mulheres têm humor e que podem transformar temas importantes em piadas carregadas de crítica social. No humor feminista, as mulheres não apenas riem de si mesmas, mas também da sociedade em seu todo. Nina Hemmingsson, Malin Biller e Liv Strömquist são alguns exemplos dessa produção, que é bem mais ampla e envolve uma geração de mulheres, entre os 30 e 40 anos de idade, que vêm inspirando os novos talentos, que enchem todos os anos as salas das escolas de quadrinhos suecas e os institutos de arte.

Se o movimento feminista, principalmente através dos coletivos, criou na Suécia uma legião de mulheres empoderadas que passaram a denunciar as contradições de uma sociedade na qual, apesar de todos os avanços, ainda há muito o que ser conquistado, notadamente no mercado de trabalho, no Brasil, por exemplo, tem crescido o número de mulheres que, por meio de fanzines e histórias em quadrinhos, vêm combatendo o machismo e falando sobre aquilo que sempre foi considerado tabu pela sociedade: sexo, masturbação e o próprio corpo feminino. Mulheres que estão se profissionalizando e transformando os quadrinhos em algo mais do que um mero entretenimento.

Apesar de todas as particularidades da trajetória das mulheres suecas na cena dos quadrinhos e do próprio feminismo sueco, éimpossível negar as semelhanças entre os dilemas enfrentados pelas profissionais que atuam no mercado dos quadrinhos nos países ocidentais. Se as suecas hoje constituem aproximadamente metade das produtoras de quadrinhos em seu país, elas ainda precisam lutar por melhores salários e por meios de se manterem financeiramente atuando apenas dentro de sua área. Os quadrinhos de humor suecos denunciam o patriarcalismo ainda reinante na sociedade sueca e os limites que a política de igualdade de gêneros encontra naquele país. A Suécia não é ainda um paraíso para as mulheres, mas caminha no sentido de ampliar cada vez mais suas oportunidades e vem ganhando a batalha contra o machismo. Se ainda há homens e mulheres que nutrem preconceitos de gênero, atualmente eles são em número reduzido se comparado a décadas anteriores, tanto pelo papel que a educação vem desempenhando naquele país quanto pela vontade política investida em ações sociais e culturais pelo governo sueco.

É possível verificar, no humor das três quadrinistas analisadas, o desejo permanente de mudança por parte de mulheres fortes e maduras que encontraram nas artes e na comunicação não apenas uma forma de sustento mas, sobretudo, um 
espaço no qual podem exercer seus direitos políticos, podem se expressar livremente e romper tabus que há séculos estão arraigados na sociedade ocidental. O humor das mulheres é um dos caminhos para a sua libertação.

\section{Referências}

BROSTRÖM, Sara. Feministiska serier - en ny typ av uttryck (2011). Disponível em: $\quad$ http://tidningenkulturen.se/index.php/konst/essaeer-om-konst/10369feministiska-serier--en-ny-typ-av-uttryc>. Acesso em: 22 mai. 2018.

FALARDEAU, Mila. Femmes et Humour. Paris: Hermann Éditions, 2014.

FIGUEIREDO, Camila Augusta Pires de. Fazendo sentido a partir dos pedaços: a colagem em Art Spiegelman. Anais das 2ª Jornadas Internacionais de Histórias em quadrinhos, Escola de Comunicações e Artes - Universidade de São Paulo, ago. 2013, p. o1-15. Disponível em: <http://www2.eca.usp.br/anaiszajornada/anaiszasjornadas/ anais/5\%20-\%2oARTIGO\%20-\%20CAMILA\%20AUGUSTA\%2oFIGUEIREDO\%20 -\%20HQ\%2oE\%2oARTE.pdf>. Acesso em: 22 jul. 2018.

FUJIWARA, Erika. An analysis of Contemporary Manga Culture in Japan and Sweden with a study of the works of Naoki Urasawa. A Master's Thesis for the Degree "Master of Arts (Two Years) in Visual Culture. Lunds Universitet, Lund, 2010.

HEMMINGSSON, Nina. Jag Är din Flick vä Nu. Stockholm: Kartago, 2016.

DELPY, Christine. Patriarcado (teorías do). In: HIRATA, Helena. Dicionário Crítico do Feminismo. - São Paulo: UNESP, 2009.

JONSSON, Angelica, GREFVE Linnea. "Ska jag kniva dig med laserkniven!" skriker Anton En studie om barnböckers förändring ur ett genusperspektiv (2015), 39p. Disponível em: <http://www.diva-portal.org/smash/get/diva2:903548/FULLTEXTo1. pdf>. Acesso em: 22 jun.2018.

LAURETIS, Teresa de. Tecnologia de Gênero. In: HOLLANDA, Heloisa Buarque de. Tendências e impasses. O feminismo como crítica da cultura. - Rio de Janeiro: Rocco, 1994.

LINDBERG, Ylva. The power of laughter to change the world: Swedish female cartoonists raise their voices. SJoCA Scandinavian Journal of Comic Art, 2016. Vol. 2, no 2, p. 3-31. Disponível em: <http://sjoca.com/wp-content/uploads/2016/o6/SJoCA2-2-02-Lindberg.pdf>. Acesso em: 16 jun. 2018. 
------. Satiriska feministiska serier: Nina Hemmingsson och Liv Strömquist. Tidskrift för litteraturvetenskap. Stockholm, vol 44, n. 2, 2014, p. 83-99. Disponível em: <http:// urn.kb.se/resolve?urn=urn:nbn:se:hj:diva-20624>. Acesso em: 12 jun. 2018.

LIV Strömquist. Disponível em: <https://en.wikipedia.org/wiki/Liv_ Str\%C3\%B6mquist>. Acesso em: 12 jul. 2018.

MAZUR, Dan, DANNER, Alexander. Quadrinhos História Moderna de uma Arte Global - de 1968 até os dias de hoje. São Paulo: Martins Fontes, 2014.

NOGUEIRA, Natania A da Silva. Malin Biller bedessinatrice suédoise. Paris: Papiers Noichkelés, n. 55, 2017.

ORLANDI, Eni Puccinelli. Análise de Discurso: princípios \& procedimentos. 8. ed. Campinas: Pontes, 2009.

PERROT, Michelle. Minha História das Mulheres. São Paulo: Contexto, 2007.

QUILLET, Lucile. BD: comment les femmes sont passées de Bécassine à Super Woman (2015). Disponível em: <http://bit.ly/2ypID44>. Acesso em: 14 set. 2017.

SANDSTRÖM, Stina. The Carnival Grotesque Representations offemininity in Swedish feminist comics. Visual Communication Design IADT, Dun Laoghaire, 2017. Disponível em: <http://www.stinasandstrom.com/media/StinaSandstrom_CarnivalGrotesque_ DHS.pdf>. Acesso em: 13 jun. 2018.

SCOTT, Joan. Gênero: uma categoria útil para análise histórica (1989). Disponível em: <http://bit.ly/2yKYNX3>. Acesso em: 27 mai. 2017.

SILVA, Alba Valéria Tinoco Alves. Deus e o Diabo no humor das mulheres: contos, casos e crônicas com humor escritos por mulheres. - Salvador: EDUFBA, 2015.

STRÖMBERG, Fredrik. Swedish Comics History. Malmö: The Swedish Comics Association, 2010.

SUNDQVIST, Alexandra. In: Swedish comics: your update on swedish comics, with portraits of ten Swedish artists. Stockholm: The Swedish Arts Council, 2015.

STRÖNQUIST, Liv. A origem do mundo: a história cultural da vagina ou a vulva vs. o patriarcado. 1플 Ed. - São Paulo, Quadrinhos da Cia, 2018. 
SUNDHALL, Jeanette. Drawing resistance - Swedish cartoonists and their relation to politics, power and the art of making others laugh. Master's Thesis in Gendering Practices 30 hec Faculty of Arts, Department of Cultural Sciences, Univesity of Gothemburg, Spring 2016.

WIHLKE, Ola. Seriebok: "Det kändes lugnt när mina känslor dog” (2016). Disponível em: <https://bearbooks.se/tag/feministiska-serier/>. Acesso em: 22 mai. 2018.

Recebito: 05.07.2018

Aceito: 11.10 .2018 